\title{
BOSQUEJOS DE LO UNIVERSAL: LA APERTURA DEL LENGUAJE EN TRILCE, ALTAZOR Y EN LA MASMÉDULA
}

Sketches of the universal: the opening of language in Trilce, Altazor and

En la masmédula

Niels Rivas Nielsen*

\section{Resumen}

Este trabajo propone una aproximación a tres obras centrales de la poesía latinoamericana: Trilce, Altazor y En la masmédula, tomando como base la confrontación entre las limitaciones que el lenguaje necesariamente impone y la voluntad radicalmente transgresora que estos textos exhiben. En particular, el trabajo explora la tensión entre la tendencia del lenguaje a fragmentar la realidad mediante conceptos y la aspiración a la unidad -la superación de toda fragmentación- que denotan los procesos verbales desplegados en estas obras. Para profundizar el análisis, se propone un diálogo entre el lenguaje poético y el pictórico, tomando como referencia los planteamientos teóricos de Piet Mondrian y su visión acerca de la relación entre lo "individual" (la fragmentación) y lo "universal" (la unidad).

Palabras clave: Crítica del lenguaje, experimentación poética, Trilce, Altazor, En la Masmédula.

Abstract

This article presents an approach to three masterpieces of Latin American poetry: Trilce, Altazor, and En la masmédula, based on the confrontation between the limitations that language necessarily entails and the rule-breaking attitude that these poetical works display. Specifically, this study explores the tension between the tendency to divide reality into segments inherent in language and the quest of unity -the cancellation of any kind of segmentation- that underlies verbal processes in Trilce, Altazor, and En la masmédula. In order to deepen the analysis, this work poses a significant connection between poetical and pictorial language, taking as reference Piet Mondrian's theoretical contributions about the relationship between "individual" and "universal" forms.

Key words: Critique of language, poetical experimentation, Trilce, Altazor, En la Masmédula.

\section{LA INDIGENCIA DE LA REALIDAD}

Juzgar la realidad exterior como insuficiente. Cuestionar la legitimidad del llamado "mundo objetivo". Conciencia de una fractura. Disidencia. Desde el romanticismo en adelante, la creación poética se desarrollará en gran parte impulsada por una experiencia de profunda insatisfacción y escepticismo: hacia la razón, hacia la mentalidad ilustrada. A juicio de Alfredo de Paz, el elemento que unifica el movimiento romántico por toda Europa lo constituye, precisamente, "la condena radical de cualquier racionalismo, la glorificación de la intuición, del sentimiento y de la pasión [...] como únicas fuerzas redentoras de un mundo cuya norma era la mediocridad" (50). Para el sujeto romántico, la realidad circundante está 
determinada por el imperio de la razón y, en consecuencia, está condenada a una estrechez que suscitará a la vez su disconformidad y su deseo, su malestar y su nostalgia. Esta disposición anímica, en la que el mundo exterior se ha convertido en un territorio contrario a las ambiciones del espíritu ${ }^{1}$, será uno de los rasgos centrales del contexto en el que se producirá el desarrollo de las vanguardias, más de un siglo después. Por cierto, los poetas franceses de la segunda mitad del siglo XIX jugaron un rol fundamental para que se produjese dicha continuidad. En palabras de Anna Balakian:

La más consciente realización de esta crisis espiritual causada por el progreso científico se manifestó en la obra breve y violenta de Isidore Ducasse, Conde de Lautréamont. [...] Dotado de inclinaciones místicas, él habría deseado vivir en un mundo que hubiese podido modelar con sus propias manos. El suyo habría sido un mundo de milagros, metamorfosis y revelaciones. En cambio, tuvo la desgracia de vivir en una época que estaba barriendo con los milagros y reemplazándolos por las inquebrantables leyes físicas (108).

Esta oscilación entre la desazón y la ambición existenciales que Balakian señala como rasgo distintivo de Lautréamont, puede distinguirse en toda la corriente simbolista. Basta recordar la obra de Baudelaire y, en particular, la confrontación sistemática entre "Spleen" e "Ideal" que marca el desarrollo de Las flores del mal. Se trata de una visión que, por un lado, desprecia la realidad exterior y, por otro, redime su propia impotencia mediante el deseo de una experiencia superlativa e inasible. Así lo evidencia el siguiente comentario de Hugo Friedrich: "en Baudelaire los dos polos, es decir, el del mal satánico y el del ideal vacuo, sirven para mantener despierta aquella excitación que hace posible la huida del mundo de la trivialidad. [... . Lo desconcertante de la modernidad baudeleriana es que está atormentada hasta la neurosis por el impulso de huir de la realidad, pero por otra parte se siente incapaz de crear una trascendencia con contenido preciso y lógico" (64).

La tensión entre la mediocridad que se le adjudica al mundo exterior y el anhelo urgente y ciego de trascendencia, constituye, igualmente, uno de los motores de la obra de Rimbaud. Javier del Prado señala que la característica rebeldía del poeta francés hunde sus raíces en "la imposible concordancia entre realidad y deseo, en la toma de conciencia de que la vida que vivimos es una insuficiencia: por eso la verdadera vida está ausente" (66). En esta misma línea, Albert Beguin sostiene: "si Rimbaud rechaza lejos de sí todo lo que pertenece al mundo terrestre, es porque a su vez se orienta hacia un paraíso vislumbrado al

\footnotetext{
${ }^{1}$ Al hablar de "ambiciones del espíritu" vale la pena recordar la descripción que Albert Beguin desarrolla en su exhaustivo estudio acerca del romanticismo alemán: "todo el empeño de los románticos tiende a rebasar las apariencias efímeras y engañosas para llegar a la unidad profunda, la única real, de manera que se esfuerzan por encontrar todo lo que en nosotros puede sobrevivir de nuestros poderes anteriores a la separación" (106). En igual dirección se orienta la visión que propone Harold Bloom acerca de los principales exponentes del romanticismo inglés: "Keats se aproxima a ese acto supremo de la imaginación romántica, tan dominante en su maestro Wordsworth: la fluida disolución o desvanecimiento donde los límites del tiempo y el espacio desaparecen, y las fronteras entre el ser y el no ser, la vida y la muerte, parecen derrumbarse" (315).
} 
cual siente pertenecer [...] Hay que recobrar a cualquier precio los métodos que nos permitan ser dueños del mundo o perdernos en la inmensidad cósmica [...] En un intenso abandono a las sensaciones, es donde Rimbaud busca el éxtasis que le permita llegar a la contemplación de la eternidad" (466).

Como se puede deducir de los ejemplos anteriores, la idea de que la realidad exterior se había adelgazado sustancialmente, convirtiéndose en un territorio desencantado, carente de profundidad y de misterio, germinó con fuerza más que suficiente durante el siglo XIX, para convertirse, al despuntar el siglo siguiente, en una de las piedras angulares de las poéticas vanguardistas. En el surrealismo esto se percibe con singular claridad. En su análisis del primer manifiesto de André Breton, el poeta y crítico Juan Eduardo Cirlot subraya esta apreciación:

El tono (del Manifiesto) es altanero y desdeñoso. Comienza por una declaración contra la vida, considerándola esencialmente como insuficiencia; hace un inventario de los pobres motivos de felicidad cotidiana, de las conquistas de la razón y de la miseria del destino humano. Salva de esta visión pesimista la independencia de la infancia y señala cómo las imperiosas necesidades prácticas conspiran para destruir implacablemente los poderes de esas etapas ensoñadoras de la vida. Abominando el positivismo y el realismo, llega Breton a defender el "derecho a la locura" contra la general sumisión a los principios de la lógica, del sentido común, de la coherencia de lo habitual (128).

La "esencial insuficiencia" que se le atribuye a la realidad objetiva no solo movilizará las búsquedas metafísicas del surrealismo sino que, en un marco más amplio, puede ser considerada como el detonante de uno de los procesos artísticos más importantes ocurridos a fines del siglo XIX y principios del XX, a saber, la consagración de la autonomía de la obra de arte, el descrédito y abolición de la obligación mimética. Pues ¿qué valor tendría emplear la palabra poética para expresar una realidad mediocre? Si la realidad circundante es concebida como insuficiente, ¿por qué la poesía y el arte en general tendrían que guardarle algún tipo de lealtad? ¿por qué tendrían que reconocer en ella la verdad o la belleza? Frente a una realidad empobrecida por "el Estado, el orden público y sus coacciones, el bienestar establecido, el curso convencional del amor y de las familias, el cristianismo, la moral" (Raymond, 30), el poeta elige dirigir su mirada fuera de las coordenadas del mundo que lo rodea. Ahí podrá presenciar la eclosión de inéditas imágenes e intuiciones. Más aún, podrá ser su artífice. Empieza, con esta aspiración, un proceso creciente y sistemático de experimentación poética: la búsqueda de realidades no objetivas conlleva una "voluntad de ruptura, disonancia y distorsión de los modelos literarios establecidos" (Verani, 30).

\section{BELLEZA NATURAL, BELLEZA ARTÍSTICA}

La independencia de la poesía promueve el tránsito desde la "realidad natural" a una "realidad artística", desde el mundo objetivo a una realidad configurada y sostenida por el lenguaje. "El poeta crea fuera del mundo que existe el que debiera existir" 
(Huidobro, Obra poética, 1297) sostiene Huidobro, expresando certeramente este significativo giro ${ }^{2}$. Pero ¿qué diferencia percibimos, concretamente, entre ambos mundos?, ¿qué se obtiene -qué acontece-en este tránsito desde una realidad a otra?

Llegado este punto, es útil recurrir a una formulación efectuada ya no en el plano de la literatura o de la filosofia sino del arte. Sobra decir que durante las primeras décadas del siglo XX las vanguardias desarrollaron sus planteamientos acerca de poesía y pintura de forma prácticamente simultánea, tornándose muchas veces indiscernibles los límites entre uno y otro ámbito: lenguaje verbal y lenguaje pictórico respondían a las mismas motivaciones y directrices. El mejor ejemplo de ello lo constituye el cubismo: la estética de los cuadros de Picasso y Gris fue asimilada por Guillaume Apollinaire y transformada en práctica literaria, en poética. Multiplicidad de perspectivas, simultaneidad, yuxtaposición de imágenes, fragmentación de la forma, todas estas nociones extraídas del ámbito visual encontraron una exacta y profusa aplicación en la vanguardia literaria cubista que se desarrolló entre los años 1915 y 1920, teniendo como principales exponentes al ya citado Apollinaire, Reverdy y la obra temprana de Vicente Huidobro.

Dicho lo anterior, me interesa introducir los planteamientos de Piet Mondrian respecto del abstraccionismo, pues considero que estos ofrecen un sustento teórico especialmente apropiado para profundizar en la distinción entre "realidad natural" y "realidad artística" y, consecuentemente, en las razones que impulsan al artista a trasgredir los códigos de representación.

Mondrian parte de una concepción de mundo basada en la distinción de una dimensión material y otra espiritual. De acuerdo con su planteamiento, la dimensión material corresponde a la realidad tal como esta se nos presenta: la realidad de las apariencias, inmediatamente visible y perceptible por los sentidos. Esta primera dimensión de lo existente se encuentra sometida a la temporalidad, al espacio y a la subjetividad de nuestras percepciones, y por lo mismo tiene carácter perecedero y relativo. Y sobre todo tiene un carácter "individual": en la naturaleza vemos las cosas aisladamente, vemos formas limitadas en sí mismas, desvinculadas las unas de las otras. Por esta razón, la naturaleza tiene para Mondrian un carácter trágico, pues en ella las cosas se nos presentan desgarradas del todo, separadas de su vínculo primordial con el mundo.

La dimensión espiritual presenta características muy distintas. En primer lugar, esta no se manifiesta directamente. Lo espiritual, sostiene Mondrian, está contenido en la realidad natural y al mismo tiempo velado por las formas naturales, de modo que es necesario trascender el aspecto inmediato de las cosas para llegar a su aprehensión. Por

\footnotetext{
${ }^{2}$ La cita pertenece al texto "La poesía", breve manifiesto leído por Huidobro el año 1921 en el Ateneo de Madrid -en pleno apogeo de las vanguardias-y publicado en 1931, como prólogo a la edición madrileña de Temblor de cielo. Otro ejemplo acerca de este punto lo constituye el consabido non serviam que Huidobro le espeta a la naturaleza, en su texto homónimo, leído en el Ateneo de Stgo. en 1914 y publicado por primera vez en 1945, en la Antología de Vicente Huidobro de E. Anguita: "Non serviam. No he de ser tu esclavo, madre Natura; seré tu amo [...] Yo tendré mis árboles que no serán como los tuyos, tendré mis montañas, tendré mis ríos y mis mares, tendré mi cielo y mis estrellas. Y ya no podrás decirme: ese árbol está mal, no me gusta ese cielo [...] los míos son mejores" (Obra poética, 1295).
} 
otra parte, la dimensión espiritual no se encuentra sometida a los accidentes de la apariencia. En oposición al carácter caprichoso y caótico de lo natural, lo espiritual tiene un carácter armónico, eterno, necesario. Y por sobre todo, un carácter "universal": lo espiritual es lo que subyacentemente comunica y une a todas las cosas entre sí.

De esta manera, el objeto último del arte consistirá para Mondrian en superar la emoción trágica que suscita la realidad material. Esta es la razón más poderosa que lo impulsa a elaborar los fundamentos de un nuevo arte, liberado de la obligación mimética. El arte mimético, el arte realista cuyo objeto es el dato "natural" proveniente del exterior, permanece en la esfera trágica. Por eso el artista abstracto desatiende la belleza natural: esta es una belleza dolorosa, una belleza que mantiene activa la experiencia de la fractura.

Los planteamientos de Mondrian añaden una nueva perspectiva para entender el porqué de la "insuficiencia" de la realidad, de la "mediocridad" y del carácter "empobrecido" que autores como Breton, Baudelaire, Lautréamont le adjudican al mundo objetivo. Tales percepciones, en último término, se explican por el hecho de que la realidad visible nos presenta solo el rostro externo-individual de las cosas; en ella, las cosas se muestran escindidas, despojadas de su universalidad. Por tanto, el nuevo arte promovido por Mondrian tendrá como objeto ya no la belleza natural-visible sino la artística, una belleza emancipada de la "indigencia", cuyo propósito apuntará a expresar la vibración de lo universal que subyace tras las formas individuales-aparentes. El siguiente fragmento de su texto Realidad natural, realidad abstracta ${ }^{3}$ resume estas consideraciones: "La forma natural caprichosa no puede suscitar en nosotros esa gran paz a la cual aspiramos interiormente [...] Liberados del apego a lo exterior podemos sobrepasar lo trágico y contemplar conscientemente, en todas las cosas, el reposo de lo universal" (Realidad natural, 23-24).

Las ideas de Mondrian responden a una sensibilidad transversal, propia de su época, y en consecuencia profundamente arraigada en el programa literario de las vanguardias. En este sentido, basta recordar las Meditaciones estéticas ${ }^{4}$ de Apollinaire, donde el poeta francés declara que "la verosimilitud ya no tiene ninguna importancia, porque el artista lo sacrifica todo a las verdades, a las necesidades de una naturaleza superior que él supone sin descubrirla" (17).

Pues bien, la autonomía del arte parece encontrar aquí su causa más honda. El pintor y el poeta se liberan de la realidad natural para acceder a una experiencia de orden metafísico: la intuición de lo "Uno primordial", en términos nietzscheanos; la restauración -siempre momentánea, evanescente- de la "unidad perdida", según el vocabulario de los románticos; Apollinaire, a su vez, lo plantea en

\footnotetext{
${ }^{3}$ Libro publicado por Mondrian en la revista De Stijl, a lo largo de trece entregas entre 1919 y 1920. Fundada en 1917 por el mismo Mondrian y Theo van Doesburg, De Stijl "recogió en breve tiempo las mejores energías pictóricas orientadas en sentido abstracto" (De Micheli, 248), convirtiéndose en un importante catalizador del espíritu experimental que dominó la escena artística durante las primeras décadas del siglo XX.

${ }^{4}$ Apollinaire publicó Meditaciones estéticas. Los pintores cubistas en París en 1913. El texto es un reflejo ejemplar del "clima de fervor intelectual en el que nació el cubismo" (De Micheli, 305).
} 
términos espirituales, similares a los que emplea Mondrian: "El arte actual -sostiene-, sin ser emanación directa de creencias religiosas determinadas, presenta sin embargo varios rasgos del gran arte, es decir del Arte Religioso" (22). ${ }^{5}$

\section{ANULAR LA LIMITACIÓN DE LO INDIVIDUAL.}

Mondrian plantea la necesidad de liberar el objeto de su individualidad, vale decir, de todas las irregularidades, contornos y gestos de su forma natural-exterior, como una manera de "despejar el camino" hacia su dimensión interna. Para ello, la principal operación del lenguaje pictórico tradicional consiste en eliminar toda curvatura o cerrazón de la línea, "tensándola" o "estirándola" hasta convertirla en línea recta. De acuerdo con la percepción de Mondrian, la línea curva o angulosa señala la existencia de un contorno, de una cierta forma que busca diferenciarse y afirmar su individualidad, mientras que la "extensión" de la línea recta señala la supresión de toda forma diferenciada, transformándose en expresión de la ausencia de límites y disolución de lo individual. "Lo universal -sostiene Mondrian-se expresa en la línea por lo recto y en la relación por lo equilibrado" (La nueva imagen, 24) ${ }^{6}$. Por tanto, "si la extensión es lo fundamental, entonces tiene que ser también lo fundamental en la imagen [...] Hay que anular la limitación de lo individual en la imagen, pues solo entonces la extensión se expresa con toda su pureza" (39).

Apertura de la forma cerrada. "Extensión" de lo curvo hasta su transformación en línea recta. Supresión de los contornos individuales para posibilitar, en la representación plástica, la manifestación de lo universal. La elección de estos procedimientos explica la simpatía del pintor holandés hacia la estética cubista. Es posible recordar que esta corriente marca un avance fundamental en la historia de la pintura, precisamente, por provocar una ruptura en la linealidad de la forma y mitigar así la limitación espacial y temporal del objeto. Mondrian interpreta esta operación estética como un primer paso en la búsqueda de universalidad propia del arte moderno. "El cubismo -sostiene- rompió la línea cerrada, el contorno, que actuaba como límite de lo individual" (100).

Pues bien, proyectando lo anterior al plano de la poesía, vemos que el lenguaje nos sitúa, precisamente, en la esfera de las formas individuales. En efecto, el sentimiento trágico al que alude Mondrian es parte constitutiva del lenguaje: en la medida en que creamos conceptos, creamos también fronteras, límites, divisiones en el seno de lo existente. Hablar es experimentar la escisión. Más aún: es provocar la escisión, es hendir el flujo de la realidad con el escalpelo de la expresión conceptual. En

\footnotetext{
${ }^{5}$ En esta misma línea, Mircea Eliade, en Lo sagrado y lo profano, señala que en el arte moderno lo sagrado se halla camuflado en formas y significaciones profanas. Ante el decaimiento de la religión institucionalizada, el arte canalizaría las inquietudes espirituales de las sociedades occidentales modernas.

${ }^{6}$ Esta cita fue extraída del libro La nueva imagen en la pintura. Mondrian lo publicó por entregas en la revista De Stijl durante1917 y 1918.
} 
consecuencia, una de las mayores preocupaciones de la poesía a partir de las primeras décadas del siglo XX consistirá en superar esta esencial paradoja: ¿cómo escribir sin desgarrar lo nombrado?, ¿sin arrancarlo de su pertenencia a la totalidad? ¿Existe un lenguaje capaz de eludir o morigerar semejante pérdida?, ¿capaz de singularizar la cosa y al mismo tiempo señalar su trascendencia, su integración al flujo superlativo que la precede y envuelve?

\section{RUPTURA DE LA FORMA EN TRILCE, ALTAZOR Y EN LA MASMÉDULA ${ }^{7}$}

Las obras señaladas en el título de este apartado comparten un rasgo distintivo: sobre la base de la radical experimentación verbal que proponen, en cada una de ellas es posible advertir una ambición similar a la del abstraccionismo propuesto por Mondrian. Las tres despliegan un lenguaje que experimenta múltiples conmociones, una de ellas implica una profunda alteración de las formas individuales. Así como la pintura de Mondrian propone "romper" y "extender" las formas cerradas y limitadas de la naturaleza, en distintos momentos de Trilce, Altazor y En la masmédula se observan mecanismos poéticos orientados a "romper" y "extender" la cerrazón semántica del concepto: abrir la palabra, forzar su contorno, disolver las delimitaciones impuestas por la arquitectura del lenguaje. A continuación me propongo explorar cuáles son, concretamente, los mecanismos empleados por Vallejo, Huidobro y Girondo para acometer semejante empresa, a partir de estas palabras -fragmentos de realidad individual- experimentan un proceso de creciente apertura, volcándose hacia un horizonte de continuidad ${ }^{8}$. Empezaré con el siguiente fragmento de Trilce:

Este cristal aguarda ser sorbido

en bruto por boca venidera

\footnotetext{
${ }^{7}$ Publicadas en 1922, 1931 y 1956 respectivamente, Trilce, de César Vallejo; Altazor, de Vicente Huidobro; y En la masmédula, de Oliverio Girondo, llevan el afán de ruptura y la exploración del lenguaje propios de las vanguardias a una de sus manifestaciones más radicales. Cabe citar las palabras del crítico Hugo Verani, quien señala: "sin estridencias, se publica en 1922 la obra más perdurable de la vanguardia latinoamericana: Trilce" (30), libro que a su juicio constituye un punto de inflexión en el tratamiento de la escritura y en el que "la desarticulación expresionista del lenguaje, de la sintaxis y de la forma" (30) ilustra de forma ejemplar "la voluntad de ruptura, disonancia y distorsión de los modelos literarios establecidos" (30). Por su parte, Saúl Yurkievich resalta el impacto de Altazor al afirmar que en esta obra la poesía se convierte en "lenguaje de la creación" (Cuanto miren, 19), alcanzando "la máxima autonomía referencial, formal, figurativa y lingüística. Nadie puede sobrepasar los confines de lo concebible y lo comunicable marcados por este texto limítrofe. Altazor es aventura y hazaña irrepetibles" (19). En la masmédula, por cierto, se aparta cronológicamente del periodo abarcado por las vanguardias, pero quizás este mismo hecho permite considerarla como un espléndido colofón de las mismas. No en vano Enrique Molina destaca de esta obra atributos similares a los de Trilce y Altazor. "La estructura misma del lenguaje sufre el impacto de la energía poética desencadenada en este libro único", sostiene el crítico y poeta argentino (34). En la masmédula, añade, cada frase opera como un "sismo psíquico", provocando un impacto "sin tregua en el que el intelecto y la sensibilidad son agitados al unísono con la misma violencia" (36).

${ }^{8}$ Cabe precisar que el enfoque ha sido elaborado a partir de textos seleccionados de Vallejo, Huidobro y Girondo, no de la totalidad de sus obras.
} 
sin dientes. No desdentada.

Este cristal es pan no venido todavía.

Hiere cuando lo fuerzan

y ya no tiene cariños animales.

Mas si se le apasiona, se melaría

y tomaría la horma de los sustantivos

que se adjetivan de brindarse

Quienes lo ven allí triste individuo

incoloro, lo enviarían por amor,

por pasado y a lo más por futuro:

si él no dase por ninguno de sus costados;

si él espera ser sorbido de golpe

y en cuanto transparencia, por boca venidera

que ya no tendrá dientes.

Este cristal ha pasado de animal,

y márchase ahora a formar las izquierdas,

los nuevos Menos.

Déjenlo solo no más (322).

El poema, en lo inmediato, nos muestra un cristal. Acto seguido nos encontramos con un gesto orientado a extender las formas cerradas que nos presenta el lenguaje objetivo: el cristal aguarda ser "sorbido". No será observado, tocado, acariciado, quebrado: será sorbido. El cristal adquiere una consistencia improbable: se ha vuelto líquido, flujo, agua. Un par de líneas después nos encontramos con un movimiento similar: el cristal se ha transformado en "pan", en "alimento futuro". Luego, en la segunda estrofa, el cristal que es flujo, que es pan se proyecta hacia un nuevo campo semántico, nutriéndose de él: advertimos que en su interior ha poseído "cariños animales". Ya no los tiene. Sin embargo, alberga en sí la capacidad de apasionarse: "mas si se le apasiona [...] tomaría la horma de los sustantivos". A continuación, el cristal se presenta bajo la forma de un "triste individuo". Triste individuo "incoloro" que es "transparencia" que ha sido "animal" y que, en definitiva, se encamina hacia un espacio en el que resuena la desintegración y la nada: el cristal se marcha "a formar las izquierdas, los nuevos Menos". En su apertura, tiende a desaparecer. El desenlace es enigmático: "Déjenlo solo no más".

La extensión a la que alude Mondrian se ve reflejada en la progresiva apertura semántica experimentada por el objeto. Como se ha visto en este poema, gradualmente el concepto abandona su forma "cerrada" e incorpora parcelas de significado que por consiguiente no le pertenecen: el cristal deviene indistintamente líquido, animal o individuo. Sin embargo, la extensión que el poema pone de manifiesto ostenta una condición ambivalente: en su apertura, lo individual como tal se disgrega, se desvanece, deja de ser asequible, se marcha a "formar los nuevos Menos". El bosquejo de lo universal nos muestra una imagen en la que el objeto, en un mismo movimiento, se 
expande y se pierde. La aspiración a lo universal entraña el desvanecimiento de las formas pormenorizadas. El cristal ofrece una verdad última que supone la negación de su identidad objetiva.

Mondrian sostiene que es preciso "anular la limitación de lo individual en la imagen". Acaso es esto precisamente lo que propone el verso final del poema: "Déjenlo solo no más". No nombremos el cristal. No lo cobijemos con ninguna palabra. Ya que hacerlo significaría reducirlo a una forma fragmentada y sellada, reinstalarlo en el terreno de lo individual-discontinuo. "Déjenlo solo no más": preserven su apertura, mantengan viva su transversalidad, su insuperable enajenación'.

Un ejercicio muy similar se aprecia en Altazor, cuando el lector se enfrenta a las múltiples facetas que ofrece el molino. Este, lejos de permanecer encasillado en los límites de su condición, en la indigencia de su identidad individual, se abre sistemáticamente hacia una gama marcadamente variopinta y extensa de acciones, objetos, atributos, experiencias. Liberado de las restricciones del pensamiento objetivo, liberado del tiempo y de la fragmentación que este impone ${ }^{10}$, el molino adquiere la sorpresa del "descubrimiento", la luz del "nacimiento", la fuerza del "armamento", la magia del "ensoñamiento", la desazón del "aburrimiento", el silencio del "recogimiento", la amargura del "enterramiento", el fulgor del "enamoramiento"... por nombrar solo unos pocos ejemplos. Mediante sucesivas asociaciones que flexibilizan y extienden la anchura de su significado, el molino se vierte hacia campos semánticos impropios o distantes. En ese trayecto, en ese gesto de incesante apertura - "molino del portento", "molino del lamento", "molino del firmamento", "molino del juramento", "molino del conocimiento", "molino del endiosamiento", "molino del encarnizamiento", "molino del atronamiento", "molino del anonadamiento"...-, se advierte la superación de la apariencia individual. El molino es, sucesivamente, otro. Cada variación lo enajena y alimenta a la vez, exacerbando su extensión.

El énfasis en las propiedades sonoras de la expresión que se advierte en estos versos, apunta hacia el mismo fin. El vaivén de la repetición, la rima sostenida, la eufonía que acompaña cada transformación del molino, terminan por erosionar los límites objetivos del concepto: el molino, como tal, como entidad "cerrada", cede ante la cadencia y la intensidad rítmica, se abandona paulatinamente a ellas, incorporando en sí la fluidez y la pluralidad semántica de la forma musical ${ }^{11}$.

\footnotetext{
${ }^{9}$ Llegado este punto, cobran pleno sentido las apreciaciones sobre el lenguaje desarrolladas por G. Giorgi y F. Rodríguez en su prólogo al texto Ensayos sobre biopolitica: "Hablar es antinatural [...] La palabra es la muerte tanto de la cosa viva como del que habla, su asesinato diferido. Cuando hablamos perdemos la plenitud de una presencia inmediata" (17).

10 "Jugamos fuera del tiempo / y juega con nosotros el molino de viento" (Huidobro, Altazor, 84). Hecha esta declaración, comienza la creciente metamorfosis del molino.

${ }^{11}$ Por cierto, la aspiración a la música juega un rol clave no solo en este fragmento sino en todo Altazor. Ya en el primer canto nos encontramos con versos como los que siguen: "Dadme mis violines de vértigo insumiso / Mi libertad de música escapada" (Huidobro, Altazor, 43). En el contexto de trasgresión y ruptura que propone la obra, la música se convierte en herramienta privilegiada de subversión. El poeta utiliza sus "violines de vértigo insumiso"
} 


\section{Niels Rivas Nielsen}

Es factible precisar que a diferencia de lo que ocurría en el poema de Trilce antes analizado, el bosquejo de lo universal que propone el fragmento de Altazor no implica la disolución de lo individual-objetivo. Dicha forma de existencia no está condenada a desaparecer, como sugería el texto de Vallejo, sino que más bien ha de ser cuestionada y alterada al máximo. El molino, sin dejar de ser tal, sin perderse de vista, experimenta en sí la violencia de la apertura, una apertura que parece tener como horizonte la total transversalidad del objeto: el molino que alberga en sí todos los atributos, que condensa todas las experiencias, que "teje las noches y las mañanas / que hila las nieblas de ultratumba" y cuyo trigo "viene y va / de la tierra al cielo / del cielo al mar" (Huidobro, Altazor, 91) .

Para complementar las ideas anteriores, resulta útil analizar el poema "Tantan yo" de En la masmédula, el que condensa y profundiza los mecanismos expresivos que ya hemos visto en las otras dos obras. Dice el texto:

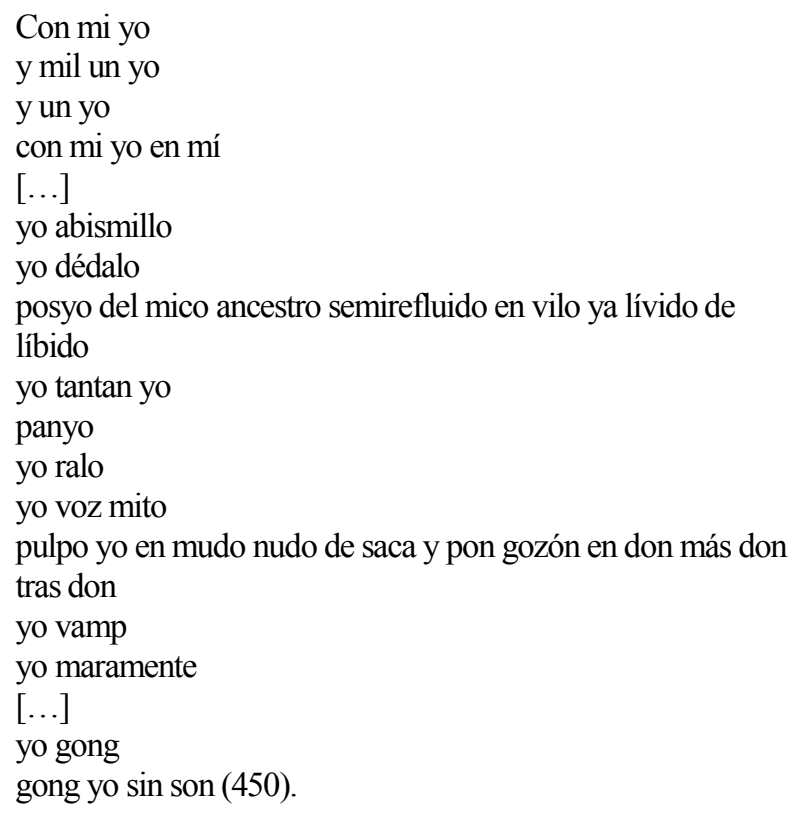

Vale la pena detenerse en el gesto que transmite el lenguaje. En él nuevamente se advierte un afán por subrayar la naturaleza mudable del objeto, su proliferación en una suerte de espiral que tiende a anular toda noción de fijeza, toda fuerza estabilizadora. Ya los dos primeros versos lo anuncian explícitamente: "con mi yo / y mil un yo". El yo se amplifica, se libera de su condición unívoca para asumir disímiles formas a lo largo del

para movilizar la disolución de las estructuras que nos brinda el orden conceptual, empujando la intelección hacia una zona resbaladiza y desconocida. En ese terreno inestable acontece, por cierto, el "vértigo", entendido como ausencia de soportes pero sobre todo como ausencia de amarras, como rebelión ante la fuerza gravitatoria del concepto. 
poema: "yo abismillo", "yo dédalo", "yo voz", "pulpo yo"... Volvemos, pues, a la idea de extensión: la cerrazón de la forma individual cede una y otra vez, con lo que el yo participa de múltiples identidades que en definitiva lo convierten en una entidad transversal: "panyo", yo total, yo exento de toda fragmentación. Tal como señala Saúl Yurkievich, en este poema Girondo lleva el yo a su extremo, "lo radicaliza, lo colma, lo satura, lo magnífica o denigra hasta el último grado, hasta tornarlo universal" (Fundadores, 213).

Llaman la atención las formas finales que asume el yo: "vamp", "maramente", "gong". La "saturación" y la "amplificación"12 que sacuden al yo y que promueven su apertura superlativa desembocan en expresiones abstractas, ajenas a toda cartografia verbal. La vibración de lo universal, como se desprende del poema, exige rutas expresivas inéditas. Esta solo puede ser pensada mediante configuraciones intelectuales liberadas de todo condicionamiento, de todo contenido impuesto por el lenguaje práctico, cuya base es la fragmentación y la existencia de demarcaciones semánticas firmemente establecidas. Así, en el límite donde el yo radicaliza su extensión, donde se encuentra a la vez con el todo y con la pérdida, con la exuberancia y con el vacío: "panyo", "yo ralo", ahí, en ese punto decisivo, el poema da un giro fundamental, enfrentando al lector a lo que Paz denomina interiorización de la visión poética, vale decir, la representación puramente subjetiva, la vivencia irrepetible que tiene lugar en la profundidad de la conciencia. "Yo vamp", "yo maramente", "yo gong": como se puede apreciar en la secuencia final del poema, el bosquejo de lo universal ha de asumir una forma expresiva rigurosamente íntima, determinada por una resonancia interna antes que por cualquier consideración de orden objetivo.

\section{IMPREVISIBLES RUTAS DE LA BELLEZA}

Se ha visto que existen analogías que nos permiten relacionar los recursos expresivos empleados en Trilce, Altazor y En la masmédula con ciertos procedimientos de la pintura abstracta. El denominador común es el deseo de suprimir las formas individuales de la realidad objetiva, romper la estructura cerrada con que se nos presenta en primera instancia el objeto $y$, consecuentemente, crear una imagen capaz de representar la intuición de lo universal, la superación de la indigencia. En su intento por lograr esto, diversos pintores que desarrollaron su obra en las primeras décadas del siglo $\mathrm{XX}$ accedieron a formas expresivas radicalmente distintas entre sí. Mondrian, Kandinsky, Malévich... cada uno de ellos desarrolló su forma particular de bosquejar lo universal. Mondrian lo hizo utilizando colores puros y elaborando formas equilibradas y

\footnotetext{
${ }^{12}$ Yurkievich utiliza estos dos términos para referirse a los mecanismos expresivos con que Girondo provoca la extensión de los objetos que entran en su corriente verbal. Tal como señala en su ensayo "La pupila del cero", incluido en el libro Fundadores de la nueva poesía latinoamericana: "Hay en Girondo un eje de exaltación vital que opera un reintegro fraterno al cosmos [...] Este eje vitalista eufórico se expresa a través de una inflación encomiástica, extremadamente emotiva [...] Esta tendencia expansiva se concreta en los textos mediante dos recursos: la saturación y la amplificación" (213).
} 
austeras $^{13}$. Kandinsky, por el contrario, eligió un derrotero formal cuyo rasgo central es la exuberancia de la línea y el color, la vibración, el estallido de múltiples combinaciones expresivas ${ }^{14}$. Malévich a su vez desembocó en la supresión de toda forma, relación y color, como lo manifiesta su "Cuadrado blanco sobre fondo blanco"15.

La pintura nos ha enseñado de forma bastante tangible que la representación de lo universal excede todo consenso. En el plano de la poesía podemos ver algo similar. Vallejo, Huidobro y Girondo comparten la aspiración de superar la limitación de lo individual, de "introducir, en el interior de un mundo fundado sobre la discontinuidad, toda la continuidad de la que este mundo es capaz" (Bataille, 23), pero a la vez cada uno de ellos elige una ruta expresiva particular. De esta manera, lo universal se nos presenta, por ejemplo, bajo el signo de una superlativa pluralidad: el molino en su intento de abrazar todos los ámbitos de la experiencia, todas las parcelas de lo real, "las noches y las mañanas", "el cielo y la tierra". En este caso, lo universal se erige a partir del reconocimiento de la naturaleza radicalmente proteica del objeto. Metamorfosis, ductilidad, apertura: tales son los trazos que conforman su bosquejo. Otro poema, en cambio, nos mostró que lo universal se configura a partir de la disolución de las formas pormenorizadas: el cristal que en su expansión se "marcha a formar las izquierdas, los nuevos Menos", recluyéndose en una soledad innominable. El objeto se redime e inmola a la vez. Se orienta hacia lo universal en la medida en que se desintegra. De igual manera, vemos en el último texto analizado que lo universal nos empuja fuera del lenguaje: el yo que es panyo, que es posyo, y cuya naturaleza última se resuelve en una secuencia de formas abstractas, inasignables para el discurso establecido: vamp, maramente, gong. Sería difícil encontrar un ejemplo que ilustre de mejor manera que este la idea rimbaudiana de la "invención de lo desconocido": la intuición visionaria exige romper las fronteras de la palabra, perforar la trama verbal y dejar testimonio de esa experiencia en el poema ${ }^{16}$. El resultado no puede ser otro sino el de una forma

\footnotetext{
${ }^{13}$ Mondrian, en La nueva imagen en la pintura: "Lo universal se expresa en la línea por lo recto, en el color por lo plano, lo puro, y en la relación por lo equilibrado" (24).

${ }^{14}$ Kandinsky, en Mirada retrospectiva: “Toda cosa 'muerta' palpitaba. No solamente las estrellas, la luna, los bosques, las flores, de que hablan los poetas, sino también una colilla en un cenicero, un botón blanco, paciente que nos echa una mirada desde el charco de agua de la calle [...] Todo eso me mostraba su rostro, su ser interior, el alma secreta que con más frecuencia calla que habla [...] Eso me bastó para comprender con todo mi ser y con todos mis sentidos la posibilidad y la existencia del arte que hoy se llama 'abstracto' por oposición al arte figurativo" (99).

${ }^{15}$ Malevich, en Manifiesto del suprematismo: "Decisiva es la sensibilidad; a través de ella el arte llega a la representación sin objetos, al suprematismo [...] El artista se ha desembarazado de todo lo que determinaba la estructura objetivo-ideal de la vida y del arte: se ha despojado de las ideas, los conceptos y las representaciones, para escuchar solamente la pura sensibilidad" (De Micheli, 327-328).

${ }^{16}$ En sus cartas a Georges Izambard, escritas en 1871, Rimbaud se refiere al poeta como "vidente": descifrador de signos, rabdomante capaz de reconocer y traducir la vibración esencial de cada objeto, de cada experiencia. Para alcanzar esta condición, Rimbaud recurrirá a un "largo, inmenso y razonado trastorno de todos los sentidos" (84), en el entendido de que ese tortuoso y superlativo procedimiento le permitirá acometer la tarea esencial del ejercicio poético: alcanzar lo desconocido, saltar salvajemente "hacia cosas inauditas o innombrables" (84). En ese punto, tras haber agotado "todas las formas de amor, de sufrimiento, de locura" (84), el poeta se convierte en 
expresiva nunca vista, modelada por el estremecimiento de una intuición personalísima ${ }^{17}$. Como señala Herbert Read, "It becomes necessary to violate words, to do violence to such elements [...] We are clear at the cost of being superficial and inexact. The poet, more exactingly, seeks absolute precision of language and thought, and the exigencies of this precision demand that he should exceed the limits of customary expression, and therefore invent" (96-98).

Por cierto, no tendría sentido jerarquizar de acuerdo con un criterio de verdad o de exactitud las formas expresivas a las que llegan los autores que hemos estudiado. Como señala Werner Hofmann en su análisis acerca de los fundamentos del arte moderno, "todas las formas son, en sí mismas, equivalentes. Porque cada artista ha de optar por la forma adecuada para él, en principio no puede existir una 'cuestión' de la forma. El criterio decisivo no es la forma sino la necesidad interna que obliga, por así decirlo, a elegirla" (272). La multiplicidad de trasgresiones y variantes expresivas que han surgido a partir de la necesidad a que alude la cita, no disimula la existencia de un claro hilo conductor: la poesía persigue la unión, aspira a la continuidad. En términos de Bataille: "La poesía lleva al mismo punto que todas las formas del erotismo: a la indistinción, a la confusión de objetos distintos. Nos conduce hacia la eternidad" (30).

\section{EPÍLOGO}

El sustrato lógico-racional del lenguaje promueve la segmentación de lo existente en categorías estancas, subrayando la separación de los objetos, la distinción rigurosa entre "lo uno" y "lo otro". Octavio Paz lo expresa certeramente cuando afirma que el mundo occidental se define por la formulación "esto $o$ aquello", a diferencia de otras culturas que privilegian la noción "esto $y$ aquello", o, más aún, "esto es aquello"," lo que pone de manifiesto la primacía de la fragmentación -la parcelación semántica- en nuestros procesos de aprehensión de lo real. De esta manera, el lenguaje establecido proyecta a nuestro alrededor una realidad compuesta por entidades individuales y discontinuas, impulsándonos a ver cada objeto cerrado en sí mismo, ajeno a imbricaciones, a puntos de fusión, a señales de unidad o vinculación con el conjunto de lo existente. El estudio nos mostró que diversos procesos verbales (asociaciones insólitas, saturación y amplificación

\footnotetext{
“el gran enfermo, el gran criminal, el gran maldito - iy en el supremo sabio!” (84). Así, la verdadera creación poética resulta inseparable de una radical conmoción psíquica, capaz de poner en suspenso los formatos perceptivos que rigen la vida ordinaria. Tal ambición, por cierto, requiere de la experimentación y exploración de nuevos lenguajes poéticos. En palabras de Rimbaud: "Las invenciones de lo desconocido reclaman formas nuevas" (89).

${ }^{17}$ Cobra sentido aquí la expresión de Nietzsche acerca del sujeto jovial, despierto, que se libera de la servidumbre impuesta por el "gigantesco entramado y andamiaje de los conceptos al que de por vida se aferra el hombre indigente" (200) y que, en esa renovada tesitura, se abandona voluptuosamente al exceso de su visión. En ese punto, por fuerza ha de cuestionar el lenguaje y señalar su precariedad mediante la elaboración de "metáforas rigurosamente prohibidas o concatenaciones conceptuales jamás oídas" (200).

${ }^{18}$ En El arco y la lira: "el mundo occidental es el del 'esto o aquello'; el oriental, el del 'esto y aquello', y aun el de "esto es aquello"' (Paz, 141).
} 
semántica, creación de formas abstractas, combinaciones eufónicas) presentes en Trilce, Altazor y En la masmédula, pretenden revertir ese condicionamiento fundamental. Aunque disímiles, los ejemplos analizados se desplegaron en función de una meta común: afirmar las nociones de participación, apertura, unidad; develar la continuidad profunda, suprimida por los mecanismos delimitadores del lenguaje convencional. Su lectura nos exhorta a reivindicar esa exuberancia.

Universidad Adolfo Ibáñez*

Departamento de Literatura

Av. Diagonal Las Torres 2640, of. 218-A, Peñalolén, Santiago (Chile)

niels.rivas@uai.cl

\section{OBRAS CITADAS}

Apollinaire, Guillaume. Meditaciones estéticas. Los pintores cubistas. Traducción de Lydia Vásquez. Madrid: Visor, 1994.

Balakian, Anna. Orígenes literarios del surrealismo. Traducción de Charles y Olga Burlacov. Santiago: Zig-zag, 1957.

Bataille, Georges. El erotismo. Traducción de Antoni Vicens y Marie Paule Sarazin. Buenos Aires: Tusquets, 2009.

Beguin, Albert. El alma romántica y el sueño. Traducción de Mario Monteforte Toledo. Madrid: Fondo de Cultura Económica, 1993.

Bloom, Harold. La compañia visionaria. Wordsworth, Coleridge y Keats. Traducción de Mariano Antolín Rato. Buenos Aires: Adriana Hidalgo Editora, 2003.

Cirlot, Juan Eduardo. Introducción al surrealismo. Madrid: Revista de Occidente, 1953.

De Micheli, Mario. Las vanguardias artísticas del siglo XX. Traducción de Ángel Sánchez Gijón. Madrid: Alianza, 2004.

De Paz, Alfredo. La Revolución Romántica. Madrid: Tecnos, 1992.

Del Prado, Javier. "Egoísmo y lucidez: el compromiso imposible". Prólogo. Poesía completa. Arthur Rimbaud. Madrid: Cátedra, 2005: 9-119.

Friedrich, Hugo. La estructura de la lírica moderna. De Baudelaire hasta nuestros días. Traducción de Joan Petit. Barcelona: Seix Barral, 1974.

Giorgi, Gabriel y Fermín Rodríguez (eds.). Prólogo. Ensayos sobre biopolítica. Buenos Aires: Paidós, 2007: 9-34.

Girondo, Oliverio. Obras: Poesía I. Buenos Aires: Losada, 2002.

Hofmann, Werner. Los fundamentos del arte moderno. Traducción de Agustín Delgado y José Antonio Alemany. Barcelona: Ediciones Península, 1992.

Huidobro, Vicente. Obra poética de Vicente Huidobro. Edición crítica. Ed. Cedomil Goic. Madrid: ALLCA XX, 2003.

— Altazor. Santiago de Chile: Editorial Universitaria, 2000. 
Kandinsky, Wassily. Mirada retrospectiva. Traducción de Alcira Nélida Bixio. Barcelona: Emecé editores, 2002.

Molina, Enrique. "Hacia el fuego central o la poesía de Oliverio Girondo". Prólogo. Obras. Poesía I. Oliverio Girondo. Buenos Aires: Losada, 2002: 9-40.

Mondrian, Piet. La nueva imagen en la pintura. Traducción de Alice Peels. Murcia: Colección Arquitectura. Colegio oficial de aparejadores y arquitectos técnicos, 1993.

_ Realidad natural y realidad abstracta. Traducción de Rafael Santos Torroella. Barcelona: Seix Barral, 1973.

Nietzsche, F. "Sobre verdad y mentira en sentido extramoral". Traducción de Joan B. Llinares. En Nietzsche. Vol. 1. Estudio introductorio de Germán Cano. Madrid: Gredos, 2009: 187-201.

Paz, Octavio. El arco y la lira. Obras Completas I. Galaxia Gutenberg, círculo de lectores, 1999: 37-395.

Raymond, Marcel. De Baudelaire al Surrealismo. México DF: Fondo de Cultura Económica, 2002.

Read, Herbert. Collected essays on literary criticism. London: Faber \& Faber LTD, 1962.

Rimbaud, Arthur. Obra poética y correspondencia escogida. Traducción de José Luis Rivas y Frédéric-Yves Jeannet. México DF: Universidad Nacional Autónoma de México, 1999.

Vallejo, César. Poesías completas. Madrid: Visor libros, 2008.

Verani, Hugo. Las vanguardias literarias en Hispanoamérica. México DF: Fondo de Cultura Económica, 1990.

Yurkievich, Saúl. Fundadores de la nueva poesía latinoamericana. Barcelona: Edhasa, 2002. "Cuanto miren los ojos creado sea". Prólogo. En mares no nacidos. Obra selecta de Vicente Huidobro (1916-1931). Barcelona: Círculo de Lectores, 2001: 7-23. 